\title{
Bacterial Etiology of Neonatal Sepsis, Antibiotic Susceptibility Profile, and Associated Factors at Burdwan Medical College, Burdwan, West Bengal, India
}

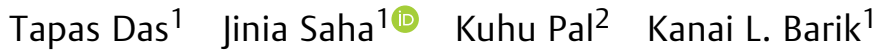 \\ ${ }^{1}$ Department of Pediatric Medicine, Burdwan Medical College and \\ Hospital, Burdwan, West Bengal, India \\ 2 Department of Microbiology, College of Medicine and JNM Hospital, \\ Kalyani, Nadia, West Bengal, India \\ Address for correspondence Jinia Saha, MD, Division of Pediatrics, \\ Department of Pediatric Medicine, Burdwan Medical College and \\ Hospital, Burdwan 713104, West Bengal, India \\ (e-mail: jiniasaha007@gmail.com).
}

J Child Sci 2021;11:e148-e154.

\begin{abstract}
Keywords

- bacterial sepsis

- antibiotic susceptibility

- early-onset sepsis

- late-onset sepsis

- neonates
\end{abstract}

Objective Neonatal sepsis remains to be a major cause of neonatal mortality and morbidity in developing countries like India. This study was aimed to identify the bacterial isolates and study antimicrobial profile among admitted babies with neonatal sepsis.

Methods A cross-sectional retrospective study was conducted in the sick neonatal wards and neonatal intensive care unit of Burdwan Medical College from March 2017 to February 2018. A total of 299 neonates suspected of neonatal sepsis was evaluated. Diagnosis of neonatal sepsis was made through positive blood culture. Positive samples were subcultured on specific media like blood, chocolate agar, nutrient, Muller-Hinton agar, and MacConkey plates, and the organisms were identified by gram staining and biochemical reactions. Antibiotic susceptibility was tested by Kirby-Bauer disc diffusion method.

Results Overall, 118 blood cultures out of 299 patients (39.46\%) were bacteriapositive. Of these, $31.3 \%$ cases had early-onset septicemia (EOS), while $68.6 \%$ had lateonset septicemia (LOS). The prevalence of sepsis was higher in males (55.9\%), preterm babies (58.47\%), and low birth weight neonates (37.29\%). The highest bacterial strains isolated were Klebsiella spp. (33.8\%) followed by Staphylococcus aureus (25.8\%), Escherichia coli (22.8\%), coagulase-negative Staphylococcus (12.5\%), Pseudomonas spp. (2.5\%), Enterococcus spp. (1.6\%), Acinetobacter spp. (0.8\%), and Burkholderia spp. $(0.8 \%)$. Resistance is high among the gram-negative bacteria, like Enterobacter and Pseudomonas, for piperacillin-tazobactam and cephalosporins but they are mostly sensitive to meropenem, colistin, and levofloxacin. Gram-positive bacteria, like S. aureus, are mostly resistant to amoxicillin-clavulanic acid but highly sensitive to linezolid, vancomycin, azithromycin, and teicoplanin.

Conclusion K. spp. and S. aureus are the most common isolates in our study. The level of resistance among the organisms toward conventional antibiotics like amoxicillin, cephalosporins, and piperacillin-tazobactum is alarmingly high. This warrants formulation of a hospital-specific guideline for antibiotic use and periodic review of the same. received

December 28, 2020

accepted after revision April 14, 2021
DOI https://doi.org/

$10.1055 / \mathrm{s}-0041-1731305$. ISSN 2474-5871. (c) 2021. The Author(s).

This is an open access article published by Thieme under the terms of the Creative Commons Attribution License, permitting unrestricted use, distribution, and reproduction so long as the original work is properly cited. (https://creativecommons.org/licenses/by/4.0/)

Georg Thieme Verlag KG, Rüdigerstraße 14, 70469 Stuttgart, Germany 


\section{Introduction}

Sepsis is one of the most common causes of neonatal deaths, globally. Prematurity, intrapartum-related complications, and birth defects are other causes of neonatal deaths worldwide. ${ }^{1}$ Most infection-related deaths in the neonatal period occur in low-income and middle-income countries due to poor hygiene and suboptimal practices for infection control. A significant proportion of these deaths are caused by multidrug-resistant pathogens. ${ }^{2}$ Despite the massive burden, few high quality data about neonatal sepsis are available from these countries. ${ }^{2,3}$ Such infection surveillance networks are a rarity in low-income and middle-income countries; the few available ones have used passive surveillance like the National Neonatal Perinatal Database (NNPD) ${ }^{3}$ and the Asia-Pacific Neonatal Infections Study (APNIS). ${ }^{4}$ Strengthening of locally owned information systems incorporating the causes of neonatal sepsis, particularly the responsible organisms and their antibiotic sensitivity patterns, can enable policy makers and program planners to use existing resources more effectively to achieve a better and effective goal.

In spite of great advances in antimicrobial therapy, neonatal life-support measures and the early assessment of risk factors, neonatal sepsis still continues to be a major cause for mortality and morbidity among neonates throughout the globe, mostly in the developing countries where reported rate of neonatal infection is 3 to 20 times higher than those reported in developed countries. ${ }^{5}$

According to onset of presentation, neonatal sepsis may be classified into (1) early-onset sepsis (EOS) that presents within the first 72 hours of life and (2) late-onset sepsis (LOS) that presents after 72 hours of age. ${ }^{6}$

The National Neonatology Forum's definition for probable sepsis is met when infant with clinical picture suggestive of sepsis with one or more of the following criteria ${ }^{7}$ : (1) Existence of predisposing factors like maternal fever or foul-smelling liquor or prolonged rupture of membrane $>12$ hours or presence of gastric polymorphs $>6 / \mathrm{hpf}$; (2) positive sepsis screen, that is, two of the following four parameters, namely, total leucocyte count (TLC) $<5,000 /$ cumm, band to total leukocytes ratio of $>0.2$, C-reactive protein (CRP) $>1 \mathrm{mg} / \mathrm{dL}$, and microerythrocyte sedimentation rate (ESR) $>15 \mathrm{~mm}$ in first hour; and (3) radiological evidence of pneumonia.

Neonatal sepsis is a broad term incorporating neonatal septicemia, meningitis, pneumonia, arthritis, osteomyelitis, necrotizing enterocolitis, and urinary tract infections. It is a medical emergency and needs prompt treatment with proper antimicrobial therapy. Moreover, increased frequency of resistance to antimicrobials is a matter of serious concern. ${ }^{8-10}$

In the United States, since the 1980s, group B Streptococcus (GBS) has been the leading cause of EOS. Despite the implementation of intrapartum antibiotic prophylaxis against GBS, it remains the leading cause of EOS in term neonates. With the increased use of intrapartum antibiotic prophylaxis for GBS, gram-negative enteric bacteria have become the main cause of EOS in preterm infants. Enteric bacilli causing EOS include Escherichia coli, Klebsiella spp.,
Pseudomonas spp., Haemophilus spp., and Enterobacter spp. Less-common organisms that can cause serious EOS include Listeria and Citrobacter. staphylococci and enterococci are more common in LOS. ${ }^{11}$ In India, the spectrum of bacterial pathogens analyzed from hospital-based data collected by NNPD network from different centers is quite different from that of developed countries, Klebsiella pneumoniae was the commonest followed by Staphylococcus aureus, E. coli, and P. spp. ${ }^{3}$

Since etiological agents and their antimicrobial susceptibility pattern may vary region wise, as well as institution wise, knowledge of the prevalence of the local isolates and their antimicrobial sensitivity pattern is of importance to start early therapy. Our study aimed to study the prevalence of local isolates in babies with established neonatal sepsis admitted in both neonatal intensive care units (NICU) and sick neonatal care unit (SNCU), as well as define the antibiotic sensitivity pattern, so that we could formulate a rational antibiotic policy for both the units.

\section{Materials and Methods}

A hospital-based, cross-sectional, retrospective study was conducted among clinically suspected cases of neonatal sepsis admitted in SNCU and NICU during the time period of March 2017 to February 2018. The features that were suggestive of clinical sepsis included refusal to suck, hypothermia, hyperthermia, poor cry, lethargy, hypotonia, absence of neonatal reflexes, bradycardia, tachycardia, gasping respiration, apnea, respiratory distress, and abdominal distension. ${ }^{6}$ Those neonates having major congenital anomalies, acute bilirubin encephalopathy, grade- 3 perinatal asphyxia, already started on antibiotics, hypoglycemia, suspected inborn errors of metabolism, and mother received antibiotics antenatally were excluded from the study. Overall, 299 neonates were chosen to be participants. The study was conducted after obtaining clearance from the ethical committee of the institution (memorandum no.: BMC-2962/ dated: December 1, 2016).

Clinical and demographic data were collected in a predesigned set of questionnaires to be filled up by each parent at the time of admission. Gestational age, associated risk factors, place of referral, method of delivery, and birth weight were noted down. Blood of $2 \mathrm{~mL}$ was collected with intravenous (IV) cannula following strict aseptic precautions, before starting empirical antimicrobial treatment, of which $1 \mathrm{ml}$ of blood was inoculated directly into pediatric aerobic blood culture bottle designed for BacT/Alert machine 3D 60 microbial system (BioMerieoux, France) with maintaining proper asepsis, and remaining blood was utilized in sepsis screening.

All the samples were transported to the side laboratory without any delay. Blood culture bottles were sent to the bacteriology laboratory of the Department of Microbiology for processing. Blood culture were followed up for 7 days, those bottles flagged positive were subcultured in MacConkey agar media, blood agar, and chocolate agar media. Bacteria are isolated and identified based on gram stain, colony morphology, and biochemical test. Antimicrobial 
Table 1 General characteristics and clinical profile of neonates with established sepsis

\begin{tabular}{|c|c|c|c|c|}
\hline Variables & $\begin{array}{l}\text { Total }(n=118) \\
n(\%)\end{array}$ & $\begin{array}{l}\text { Early-onset sepsis }(n=37) \\
n(\%)\end{array}$ & $\begin{array}{l}\text { Late-onset sepsis }(n=81) \\
n(\%)\end{array}$ & $p$-Value \\
\hline \multicolumn{5}{|l|}{ Gender } \\
\hline Males & $66(55.93)$ & $20(54.05)$ & $46(56.79)$ & \multirow[t]{2}{*}{0.781} \\
\hline Females & $52(44.07)$ & 17 (45.95) & $66(55.93)$ & \\
\hline \multicolumn{5}{|c|}{ Gestational age (wk) } \\
\hline Preterm & $69(58.47)$ & $9(24.32)$ & $60(58.47)$ & $<0.001^{\mathrm{a}}$ \\
\hline Term & $44(37.29)$ & $23(62.16)$ & $21(25.93)$ & $<0.001^{\mathrm{a}}$ \\
\hline Postterm & $5(4.24)$ & $5(13.51)$ & $0(0)$ & $0.016^{\mathrm{a}}$ \\
\hline \multicolumn{5}{|c|}{ Birth weight $(\mathrm{kg})$} \\
\hline$<1$ & $11(9.32)$ & $0(0)$ & $11(9.32)$ & $0.000^{\mathrm{a}}$ \\
\hline $1-1.5$ & $28(23.73)$ & $5(13.51)$ & $23(23.73)$ & $0.048^{\mathrm{a}}$ \\
\hline $1.5-2$ & $44(37.29)$ & $14(37.84)$ & $30(37.04)$ & 0.943 \\
\hline$>2.5$ & $35(29.66)$ & $18(48.65)$ & 17 (20.99) & $0.003^{\mathrm{a}}$ \\
\hline \multicolumn{5}{|c|}{ Mode of delivery } \\
\hline Vaginal & $65(55.08)$ & $19(51.35)$ & $46(56.79)$ & \multirow[t]{2}{*}{0.582} \\
\hline Caesarean & $53(44.92)$ & $18(48.65)$ & $35(43.21)$ & \\
\hline \multicolumn{5}{|l|}{ Outcome } \\
\hline Mortality & $15(12.71)$ & $7(18.92)$ & $8(9.88)$ & 0.171 \\
\hline
\end{tabular}

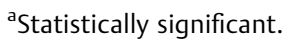

sensitivity was done by the modified Kirby-Bauer disc diffusion method following Clinical and Laboratory Standards Institute guideline. ${ }^{12}$

Two to three colonies of the isolated organisms were mixed with normal saline and turbidity of the mixture was made equivalent to 0.5 MacFarland and was swabbed over MullerHinton agar plates. Within 15 minutes, antibiotic discs (HiMedia, India) were placed with desired amounts of antibiotics and the plates were incubated overnight at $37^{\circ} \mathrm{C}$. Following antibiotic, disc was used for susceptibility testing of isolates: cotrimoxazole $(25 \mu \mathrm{g})$, amoxicillin/clavulanic acid (20/10 $\mu \mathrm{g})$, piperacillin/tazobactam $(100 / 10 \mu \mathrm{g})$, cefotaxime $(30 \mu \mathrm{g})$, ceftriaxone $(30 \mu \mathrm{g})$, ceftazidime $(30 \mu \mathrm{g})$, meropenem $(10 \mu \mathrm{g})$, imipenem $(10 \mu \mathrm{g})$, and azithromycin $(30 \mu \mathrm{g})$; aminoglycosides, such as amikacin $(30 \mu \mathrm{g})$ and gentamicin $(10 \mu \mathrm{g})$; fluoroquinolones, such as ciprofloxacin $(5 \mu \mathrm{g})$ and levofloxacin $(5 \mu \mathrm{g})$; and linezolid $(30 \mu \mathrm{g})$ and clindamycin $(2 \mu \mathrm{g})$. Minimum inhibitor concentration (MIC) of teicoplanin $(10 \mu \mathrm{g})$, vancomycin $(30 \mu \mathrm{g})$, and colistin $(10 \mu \mathrm{g})$ was determined by the Epsilometer test (E test).

\section{Statistical Analysis}

All data were put in Microsoft excel. SPSS version 20.0 (Statistical Packages for Social Sciences Inc. Chicago, Illinois, United States) was used for data analysis. Categorical variables were expressed in percentage and frequencies and compared across the groups using Pearson's Chi-square test for independence of attributes and Fisher's exact test for appropriate. An $\alpha$ level of $5 \%$ has been taken, that is, if any $p$-value was less than 0.05 , it was considered to be statistically significant.

\section{Results}

\section{General Characteristics and Clinical Profile}

Among these 299 clinically suspected cases of neonatal sepsis, blood culture was positive in 118 cases (39.46\%) while 181 samples were culture negative (-Table $\mathbf{1}$ ).

Among the culture-positive cases, 66 (55.93\%) of the neonates were males, while $52(44.07 \%)$ were females at a ratio of $1.27: 1$. The distribution of neonates according to gestational age shows the following: preterm, $58.47 \%$; term, 37.29\%; and postterm, $4.24 \%$. The distribution of neonates according to birth weight was al follows: extremely low birth weight (ELBW), 9.32\%; very low birth weight (VLBW), 23.73\%; low birth weight (LBW), $37.29 \%$; and normal weight, $29.66 \%$. Of these, $55.08 \%$ neonates were born by vaginal delivery, while $44.92 \%$ by caesarean section.

\section{Bacteriological Profile}

Distribution of blood culture isolates showed 46 (38.3\%) were gram-positive bacteria and 74 (61.6\%) were gramnegative bacteria as shown in - Table 2 . The highest bacterial strains isolated were K. spp. (33.8\%) followed by S. aureus (25.8\%), E. coli (22.8\%), coagulase-negative Staphylococcus (CoNS; 12.5\%), P. spp. (2.5\%), E. spp. (1.6\%), Acinetobacter spp. (0.8\%), and Burkholderia spp. (0.8\%).

The maximum number of bacterial strains isolated in EOS was E. coli (37.8\%) followed by K. spp. (29.7\%). However, the highest bacterial strains in LOS were K. spp. (34.94\%) followed S. aureus (28.9\%), as shown in - Table 3. 
Table 2 Bacteriological profile: frequency of isolates in culture positive sepsis

\begin{tabular}{|l|l|l|}
\hline Organism & $\begin{array}{l}\text { No of } \\
\text { isolates }(\boldsymbol{n}=\mathbf{1 2 0})\end{array}$ & Proportion (\%) \\
\hline \multicolumn{2}{|l|}{ Gram-negative organisms } \\
\hline Klebsiella spp. & 40 & 33.89 \\
\hline Escherichia coli & 27 & 22.88 \\
\hline Pseudomonas spp. & 3 & 2.50 \\
\hline Enterobacter spp. & 2 & 1.66 \\
\hline Acinetobacter spp. & 1 & 0.83 \\
\hline Burkholderia spp. & 1 & 0.83 \\
\hline Gram-positive organisms \\
\hline $\begin{array}{l}\text { Staphylococcus } \\
\text { aureus }\end{array}$ & 31 & 25.83 \\
\hline CoNS & 15 & 12.50 \\
\hline Total & 120 & 100 \\
\hline
\end{tabular}

Abbreviation: CoNS, coagulase-negative Staphylococcus.

Of these 118 patients, a total of 120 bacterial isolates were cultured with two patients having two isolated bacteria from their blood cultures, while two patients had bacteria along with isolated fungus (Candida albicans) shown in (-Table 4).

\section{Antibiotic Susceptibility Pattern Gram-Negative Bacteria}

K. spp. showed the maximum sensitivity to levofloxacin (97\%), amikacin (89\%), and meropenem (69\%) and low sensitivity to amoxicillin-clavulinic acid, cephalosporins, and piperacillintazobactum. K. spp. was highly sensitive to colistin (100\%).

E. coli had $100 \%$ sensitivity to meropenem, cotrimoxazole, and colistin; $96 \%$ sensitivity to amikacin and $80 \%$ to levofloxacin, while showed low sensitivity to antibiotics like amoxicillin, cephalosporins, and piperacillin-tazobactum.

A. spp. was highly sensitive to colistin and ceftazidime (100\%) but showed $100 \%$ resistance to rest antibiotics like gentamicin, amikacin, ciprofloxacin, levofloxacin, and cephalosporins.

P. spp. had $100 \%$ sensitivity to ceftazidime, levofloxacin, and meropenem and 50\% sensitivity to amikacin, as well as $100 \%$ resistance to gentamicin and all $\beta$-lactam antibiotics.

E. spp. showed $100 \%$ sensitivity to levofloxacin and ciprofloxacinand and $100 \%$ resistance to cotrimoxazole, amikacin, gentamicin, and ceftriaxone.

B. spp. showed $100 \%$ sensitivity to ceftazidime, meropenem, and cotrimoxazole and $67 \%$ sensitivity, as well as $100 \%$ resistance, to amikacin and gentamicin.

\section{Gram-Positive Bacteria}

CoNS was $100 \%$ sensitive to clindamycin and levofloxacin, $100 \%$ sensitive to vancomycin, $83 \%$ to amikacin, $80 \%$ to

Table 3 Bacteriological profile: frequency of isolates in early-onset and late-onset sepsis

\begin{tabular}{|c|c|c|c|}
\hline Organism & $\begin{array}{l}\text { EOS }(n=37) \\
n(\%)\end{array}$ & $\begin{array}{l}\operatorname{LOS}(n=83) \\
n(\%)\end{array}$ & $p$-Value \\
\hline \multicolumn{4}{|l|}{ Gram-negative organisms } \\
\hline Escherichia coli & $14(37.84)$ & $13(15.66)$ & $0.013^{a}$ \\
\hline Klebsiella spp. & $11(29.73)$ & $29(34.94)$ & 0.569 \\
\hline Enterobacter spp. & $1(2.7)$ & $1(1.2)$ & 0.608 \\
\hline Pseudomonas spp. & $0(0)$ & $3(3.61)$ & 0.078 \\
\hline Acinetobacter spp. & $0(0)$ & $1(0.83)$ & 0.314 \\
\hline Burkholderia spp. & $0(0)$ & $1(0.83)$ & 0.314 \\
\hline \multicolumn{4}{|l|}{ Gram-positive organisms } \\
\hline Staphylococcus aureus & $7(18.92)$ & $24(28.92)$ & 0.219 \\
\hline CoNS & $4(10.81)$ & $11(13.25)$ & 0.699 \\
\hline
\end{tabular}

Abbreviation: CoNS, coagulase-negative Staphylococcus.

${ }^{\text {a }}$ Statistically significant.

Table 4 Types of isolates

\begin{tabular}{|l|l|l|l|}
\hline Isolates & Type & No. of patients $(\boldsymbol{n}=\mathbf{1 1 8})$ & Percentage \\
\hline \multirow{3}{*}{ Single isolated organism } & Gram positive & 44 & 37.28 \\
\cline { 2 - 4 } & Gram negative & 70 & 59.32 \\
\hline \multirow{3}{*}{ Two isolated organisms } & Gram positive + gram negative & 1 & 0.84 \\
\cline { 2 - 4 } & Gram negative + gram negative & 1 & 0.84 \\
\cline { 2 - 4 } & Gram negative + Candida albicans & 2 & 1.69 \\
\hline
\end{tabular}




\begin{tabular}{|c|c|c|c|c|c|c|c|c|c|c|c|c|c|c|c|c|c|}
\hline 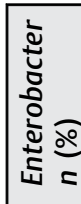 & & $\begin{array}{l}o \\
\frac{a}{o} \\
o\end{array}$ & & & & 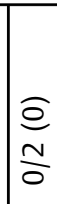 & $\begin{array}{l}a \\
\frac{a}{o} \\
o\end{array}$ & $\frac{a}{a}$ & $\begin{array}{l}a \\
\frac{a}{0} \\
\frac{v}{o}\end{array}$ & & $\mid \begin{array}{l}\bar{D} \\
\stackrel{D}{c} \\
\frac{N}{N} \\
\end{array}$ & $\begin{array}{l}\widehat{\partial} \\
\stackrel{\Xi}{\Xi} \\
\frac{N}{v}\end{array}$ & & $\begin{array}{l}\frac{\sigma}{8} \\
\frac{0}{2} \\
\frac{2}{v}\end{array}$ & $\left|\begin{array}{l}\overline{0} \\
\frac{1}{o}\end{array}\right|$ & & \\
\hline 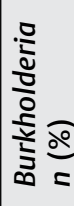 & & & & & 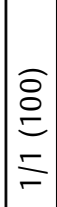 & $\frac{o}{o}$ & $\begin{array}{l}\widehat{\varrho} \\
\bar{c} \\
\bar{a}\end{array}$ & & & & 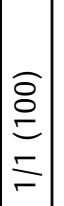 & & & & & & $\begin{array}{l}\text { o } \\
\text { 응 }\end{array}$ \\
\hline 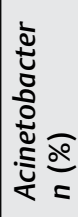 & & $\mid \begin{array}{l}\bar{e} \\
\bar{c}\end{array}$ & $\left|\begin{array}{c}a \\
\frac{0}{0}\end{array}\right|$ & & 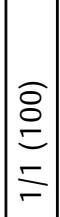 & $\frac{a}{\bar{c}}$ & $\begin{array}{l}\bar{e} \\
\bar{c}\end{array}$ & & & & & $\begin{array}{l}\text { o } \\
\bar{c}\end{array}$ & & $\frac{\hat{e}}{\bar{c}}$ & $\begin{array}{c}o \\
\bar{c} \\
\bar{o}\end{array} \mid$ & & 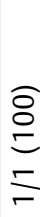 \\
\hline 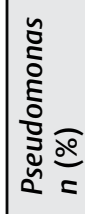 & $\begin{array}{l}\bar{a} \\
\frac{v}{o}\end{array}$ & $\begin{array}{c}o \\
\frac{m}{o}\end{array}$ & & & 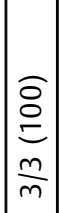 & $\begin{array}{l}\stackrel{O}{0} \\
\stackrel{i n}{N} \\
\stackrel{n}{r}\end{array}$ & $\begin{array}{l}o \\
\frac{m}{o}\end{array}$ & $\begin{array}{l}\frac{\partial}{0} \\
\frac{\mathrm{v}}{0}\end{array}$ & & & $\left|\begin{array}{c}\bar{O} \\
\stackrel{D}{c} \\
\frac{m}{m}\end{array}\right|$ & $\begin{array}{l}\frac{\sigma}{\circ} \\
\frac{m}{m} \\
\frac{m}{m}\end{array}$ & & $\begin{array}{l}\frac{\delta}{\delta} \\
\frac{\delta}{N} \\
\frac{N}{N}\end{array}$ & & & \\
\hline $\begin{array}{l}\text { zo } \\
\text { ن }\end{array}$ & \begin{tabular}{|l}
$o$ \\
0 \\
0 \\
$o$ \\
$\frac{0}{m}$ \\
\end{tabular} & $\begin{array}{l}\frac{\tilde{m}}{\stackrel{m}{y}} \\
\frac{n}{m}\end{array}$ & & $\begin{array}{l}\frac{\sigma}{ \pm} \\
\frac{1}{2} \\
\frac{5}{6} \\
\end{array}$ & \begin{tabular}{|l|}
$\widehat{\tilde{m}}$ \\
$\stackrel{0}{0}$ \\
$\underline{0}$ \\
$\bar{v}$
\end{tabular} & 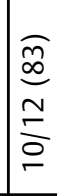 & 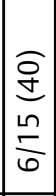 & 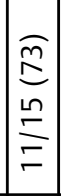 & $\begin{array}{c}\frac{a}{m} \\
\frac{m}{o}\end{array}$ & 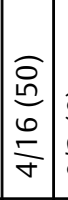 & $\begin{array}{c}a \\
a \\
\frac{a}{o}\end{array}$ & $\begin{array}{l}\widehat{\sigma} \\
\circ \\
= \\
\\
\end{array}$ & 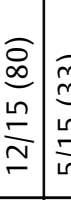 & 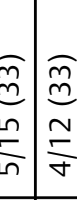 & $\begin{array}{l}\frac{O}{ \pm} \\
0 \\
\frac{9}{\sigma}\end{array}$ & 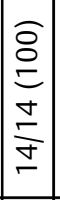 & \\
\hline
\end{tabular}

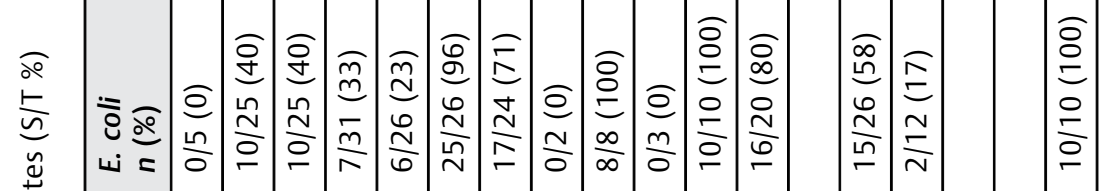

\begin{tabular}{|c|c|c|c|c|c|c|c|c|c|c|c|c|}
\hline 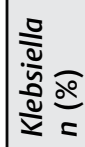 & 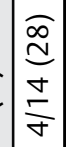 & $\mid \begin{array}{l}\infty \\
\stackrel{\infty}{=} \\
\frac{a}{m} \\
\frac{1}{r}\end{array}$ & $\begin{array}{l}a \\
\frac{a}{a} \\
\frac{a}{0}\end{array}$ & 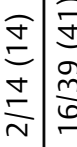 & 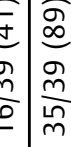 & 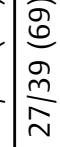 & 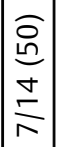 & $\begin{array}{l}\frac{\sigma}{d} \\
\frac{m}{\sigma} \\
\frac{\sigma}{\sigma}\end{array}$ & $\mid \begin{array}{l}\hat{\sigma} \\
\underline{0} \\
\underline{0} \\
\frac{N}{\infty} \\
-\infty\end{array}$ & $\mid \begin{array}{c}\hat{a} \\
\mathfrak{a} \\
o \\
\frac{m}{\infty} \\
\infty \\
m\end{array}$ & ని & $\begin{array}{l}\widehat{O} \\
\text { m} \\
\text { م } \\
\frac{m}{N} \\
\end{array}$ \\
\hline
\end{tabular}

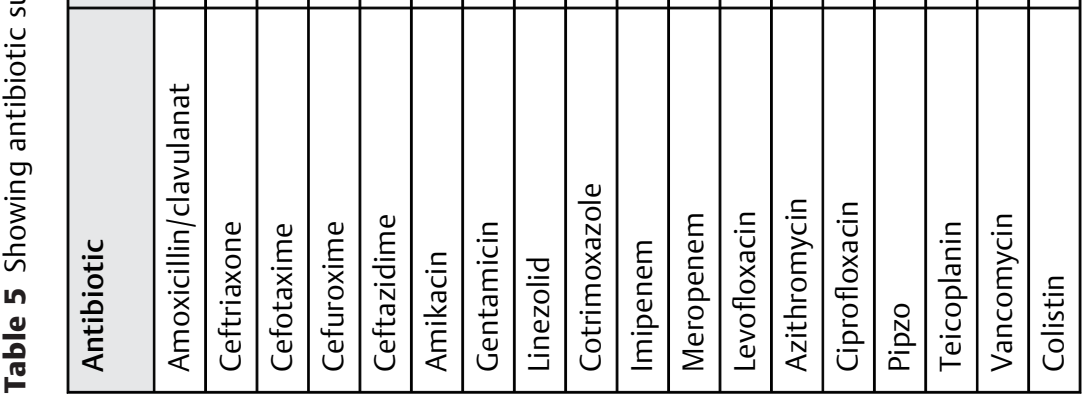


azithromycin, and 73\% to linezolid, as well as less sensitive to imipenem, ciprofloxacin, amoxicillin + clavulanic acid and cephalosporins.

S. aureus showed $100 \%$ sensitivity to vancomycin, linezolid, teicoplanin, meropenem, and imipenem and $84 \%$ to amikacin and $74 \%$ to azithromycin, as well as low sensitivity to piperacillin-tazobactam, gentamicin, ciprofloxacin, levofloxacin, cotrimoxazole, cephalosporins, and amoxicillin/clavulanate (-Table 5).

\section{Discussion}

Blood culture was positive in 118 cases, that is, $39.46 \%$ among 299 clinically suspected sepsis cases. The study shows culture-positive sepsis was much higher in male neonates (55.93\%) compared to female neonates (44.07\%). Different authors have documented that male babies are more susceptible to neonatal sepsis than female babies. ${ }^{13,14}$ The high predilection of male babies for neonatal sepsis may be due to the fact that X-chromosome is potentially more immune in comparison to Y-chromosome because of X-linked immuneregulatory genes. ${ }^{14}$

In this study, the occurrence of sepsis was much higher in preterm babies (58.47\%) in comparison to term and postterm babies. Different authors also documented higher incidence of sepsis in preterm babies and it was also directly related to the degree of prematurity, ${ }^{15,16}$ as the preterm neonates had greater compromise in their immune system. The present study is well correlated with the observation by different authors.

Out of total cases, ELBW babies were 11 (9.32\%), VLBW babies were 28 (23.73\%), LBW babies were 44 (37.29\%), and normal birth weight babies were 35 (29.66\%). The highest incidence of culture-positive sepsis was seen among LBW babies followed by normal birth weight babies. Different authors documented that LBW babies were more susceptible to develop sepsis because of their deficiency in the development of immune system along with poor transplacental acquisition of maternal immunoglobulin. ${ }^{17}$ Similar observation was also noted by Singh. ${ }^{10}$

K. spp. was the commonest organism causing neonatal sepsis (33.89\%) followed by S. aureus (25.83\%). These findings are similar with the NNPD 2002 to 2003 reports $^{3}$ and a study conducted by Jyothi et al in South India where the incidence of $K$. spp. is the highest. ${ }^{18}$ Roy et al, in a study in tertiary care hospital in northern India, have documented K. spp. as the predominant organism. ${ }^{19}$

LOS has been found to be mostly caused by K. spp. (34.94\%) followed by S. aureus (28.92\%) in this study. Studies by Verma et al in the Western part of India and Panigrahi et al in the Eastern India have also obtained similar results. ${ }^{20,21}$

E. coli $(37.84 \%)$ followed by K. spp. (29.73\%) are the commonly isolated pathogens from babies in EOS. Studies by Mendoza-Palomar et al and Stoll et al have reported that $E$. coli as an important cause of EOS. ${ }^{22,23}$

GBS is a leading cause of neonatal sepsis in developed countries but it was not isolated from our study participants.
A study by Simonsen et al has reported incidence of GBS in EOS but according to Kuruvilla et al and Viswanathan et al, GBS is rarely documented in India. ${ }^{24-26}$

Other organisms isolated in this study were CoNS, Pseudomonas, B. spp., Acinetobacter, and Enterobacter.

CoNS, as an emerging pathogen in neonatal sepsis cases, has been reported by Marchant et al. ${ }^{27}$ Sepsis due to CoNS, Pseudomonas, and Acinetobacter have been documented in the NNPD 2002 to 2003 reports. $^{3}$

Our study concluded that gram-negative Enterobacteriaceae (Klebsiella and E. coli) was mostly sensitive to meropenem, amikacin, colistin, and levofloxacin but resistant to cephalosporins and piperacillin-tazobactam. Enterobacter was resistance to most of the antibiotics except fluoroquinolones. Pseudomonas was found to be sensitive to ceftazidime, levofloxacin, meropenem, and cotrimoxazole mainly. Acinetobacter was found to be only sensitive to ceftazidime and colistin, while Burkholderia was found to be sensitive to ceftazidime, meropenem, and cotrimoxazole.

On the other hand, the gram-positive isolates (S. aureus) were mostly sensitive to amikacin, azithromycin, linezolid, and vancomycin but resistant to amoxicillin-clavulanic acid and cephalosporins. Studies by Sheth et al in the Western part of India and Viswanathan et al in the Eastern India have also found high proportion of resistance to the common first line antibiotics. ${ }^{28,29}$ CoNS was mostly sensitive to fluoroquinolones, clindamycin, azithromycin, colistin, linezolid, amikacin, and vancomycin. Almost similar type of result had been revealed from other places in India. $19,30,31$

\section{Limitations of this Study}

This is a hospital-based study involving small number of study samples. So, the results of this study may not be applied to the others hospital or community. For this, large scale multicentric study is needed. Inability to identify the anaerobes was another limitation of the study.

\section{Conclusion}

This helps us conclude that empirically chosen first line antibiotics, like ampicillin, piperacillin-tazobactam, and cephalosporins, are mostly ineffective when neonatal sepsis is suspected in our unit.

Differences of antibiotic sensitivity and resistance pattern among various studies can be explained by the regional variation of prevalent organisms and different antibiotic regimens used for treating those organisms. ${ }^{32,33}$

Neonatal mortality among the patients has been reported to be $12.71 \%$ which is similar to findings conducted by the Delhi Neonatal Infection Study (DeNIS) study. ${ }^{34}$

\section{Recommendations}

There is need to develop an antibiotic policy tailored to the type of antibiotic resistance documented in any hospital and update that at least every 2 years. 


\section{Authors' Contributions}

T.D.: data collection, conception, and designing of study; J. S.: analysis and interpretation of data and preparing manuscript; K.P.: microbiological laboratory work; K.L. B.: planning of study, treating physician, and critical revision of article. All authors reviewed and approved the final version of the manuscript for submission.

\section{Funding}

None.

\section{Conflict of Interest}

None declared.

\section{Acknowledgments}

The authors would like to express their gratitude to the Principal, and respective Heads of the Departments of Pediatrics and Microbiology, for their support.

\section{References}

1 Liu L, Oza S, Hogan D, et al. Global, regional, and national causes of child mortality in 2000-13, with projections to inform post-2015 priorities: an updated systematic analysis. Lancet 2015;385 (9966):430-440

2 Laxminarayan R, Duse A, Wattal C, et al. Antibiotic resistance-the need for global solutions. Lancet Infect Dis 2013;13(12): 1057-1098

3 NNPD Network; supported by Indian Council of Medical Research. National Neonatal Perinatal Database Network. Report for 2002-2003. Accessed March 30, 2015 at: https://www. newbornwhocc.org/pdf/nnpd_report_2002-03.PDF

4 Tiskumara R, Fakharee SH, Liu CQ et al; Asia-Pacific Neonatal Infections Study. Neonatal infections in Asia. Arch Dis Child Fetal Neonatal Ed 2009;94(02):F144-F148

5 Zaidi AK, Huskins WC, Thaver D, Bhutta ZA, Abbas Z, Goldmann DA. Hospital-acquired neonatal infections in developing countries. Lancet 2005;365(9465):1175-1188

6 Agrawal R, Deorari AK, Paul VK. Sepsis in newborn. In: AIIMS Protocols in Neonatology. 1st ed. New Delhi, India: CBS Publishers and Distributors Pvt. Ltd.; 2015:163-173

7 Joshi SG, Ghole VS, Niphadkar KB. Neonatal gram-negative bacteremia. Indian J Pediatr 2000;67(01):27-32

8 Ang JY, Ezike E, Asmar BI. Antibacterial resistance. Indian J Pediatr 2004;71(03):229-239

9 Singh M, Paul VK, Bhakoo OM, Eds. In: Neonatal Nomenclature and Data Collection. National Neonatology ForumDelhi1989: 67-68

10 Singh M. Perinatal infections. In: Care of the Newborn. 6th ed. New Delhi, India: Sagar Publication; 2004:196-216

11 Puopolo KM. Bacterial and fungal infections. In: Cloherty JP, Eichenwald CE, Stark RA, eds. Manual of Neonatal Care. 6th ed. New Delhi, India: Wolters Kluwer (India) Pvt. Ltd.; 2008:275-300

12 Performance Standards for Antimicrobial Susceptibility Test. 26th ed. Accessed May 6, 2021 at: https://webstore.ansi.org/preview-pages/CLSI/preview_CLSI+M100-S26.pdf

13 Stoll BJ. Infection of the neonatal infant. In: Kleigman RM, Behrman RE, Jenson HB, Stanton BF. Nelson's Text Book of Paediatrics. 18th ed. Philadelphia, PA: WB Saunders Co.; 2006:794-811

14 Washburn TC, Medearis DN Jr., Childs B. Sex differences in susceptibility to infections. Pediatrics 1965;35:57-64

15 Richard AP, Elvira P, Joan AR, et al. Bacterial sepsis and meningitis. In: Taeush HW, Ballard RA, Gleason CA, eds. Avery's Disease of the
Newborn. 8th ed. Philadelphia, PA: Elsevier-Saunders; 2001: 551-577

16 Takkar VP, Bhakoo ON, Narang A. Scoring system for the prediction of early neonatal infections. Indian Pediatr 1974;11(09):597-600

17 Lewis BD, Wilson CB. Developmental immunology and role of host defenses in neonatal susceptibility to infections. In: Remington JS, Klein JO, eds. Infections of Fetus and Newborns Infant. 4th ed. Philadelphia, PA: WB Saunders; 1995:20-98

18 Jyothi P, Basavaraj MC, Basavaraj PV. Bacteriological profile of neonatal septicemia and antibiotic susceptibility pattern of the isolates. J Nat Sci Biol Med 2013;4(02):306-309

19 Roy I, Jain A, Kumar M, Agarwal SK. Bacteriology of neonatal septicaemia in a tertiary care hospital of northern India. Indian J Med Microbiol 2002;20(03):156-159

20 Verma P, Berwal PK, Nagaraj N, et al. Neonatal sepsis: epidemiology, clinical spectrum, recent antimicrobial agents and their antibiotic susceptibility pattern. Int J Contemp Pediatrics 2015; 2(03):176-180

21 Panigrahi P, Chandel DS, Hansen NI, et al. Neonatal sepsis in rural India: timing, microbiology and antibiotic resistance in a population-based prospective study in the community setting. J Perinatol 2017;37(08):911-921

22 Mendoza-Palomar N, Balasch-Carulla M, González-Di Lauro S, et al. Escherichia coli early-onset sepsis: trends over two decades. Eur J Pediatr 2017;176(09):1227-1234

23 Stoll BJ, Puopolo KM, Hansen NI, et al; Eunice Kennedy Shriver National Institute of Child Health and Human Development Neonatal Research Network. Early-onset neonatal sepsis 2015 to 2017, the rise of Escherichia coli, and the need for novel prevention strategies. JAMA Pediatr 2020;174(07):e200593

24 Simonsen KA, Anderson-Berry AL, Delair SF, Davies HD. Earlyonset neonatal sepsis. Clin Microbiol Rev 2014;27(01):21-47

25 Kuruvilla KA, Thomas N, Jesudasan MV, Jana AK. Neonatal group B Streptococcal bacteraemia in India: ten years' experience. Acta Paediatr 1999;88(09):1031-1032

26 Viswanathan R, Singh AK, Basu S, Chatterjee S, Sardar S, Isaacs D. Multi-drug resistant gram negative bacilli causing early neonatal sepsis in India. Arch Dis Child Fetal Neonatal Ed 2012;97(03): F182-F187

27 Marchant EA, Boyce GK, Sadarangani M, Lavoie PM. Neonatal sepsis due to coagulase-negative staphylococci. Clin Dev Immunol 2013;2013:586076

28 Sheth KV, Patel TK, Tripathi CB. Antibiotic sensitivity pattern in neonatal intensive care unit of a tertiary care hospital of India. Asian J Pharm Clin Res 2012;5(Suppl 2):46-50

29 Viswanathan R, Singh AK, Mukherjee S, Mukherjee R, Das P, Basu S. Aetiology and antimicrobial resistance of neonatal sepsis at a tertiary care centre in eastern India: a 3 year study. Indian J Pediatr 2011;78(04):409-412

30 Arora U, Devi P. Bacterial profile of blood stream infections and antibiotic resistance pattern of isolates. J K Sci 2007;9(04):186-190

31 Kumar S, Rizvi M, Vidhani S, Sharma VK. Changing face of septicaemia and increasing drug resistance in blood isolates. Indian J Pathol Microbiol 2004;47(03):441-446

32 Polin RA, Parravicini E, Regan JA, Taeusch HW. Bacterial sepsis and meningitis. In: Avery's Disease of the Newborn 8th ed. Taeusch HW, Ballard RA, Gleason CA, eds. Philadelphia, PA: ElsevierSaunders; 551-577

33 Aftab R, Iqbal I. Bacteriological agents of neonatal sepsis in NICU at Nishtar Hospital Multan. J Coll Physicians Surg Pak 2006;16 (03):216-219

34 Chaurasia S, Sankar MJ, Agarwal R, et al; Investigators of the Delhi Neonatal Infection Study (DeNIS) collaboration. Characterisation and antimicrobial resistance of sepsis pathogens in neonates born in tertiary care centres in Delhi, India: a cohort study. Lancet Glob Health 2016;4(10):e752-e760 